Sci. Journal Impact

Factor: $6.1(2018)$

ICV: 90.90 (2018)

(c) (i) (8)

Copyright@IJCRR

\section{$\bullet$ \\ IJCRR \\ Section: Healthcare \\ Peculiarities of a Pain in Patients with Ischemic Heart Disease in the Presence of Individual Combines of the Metabolic Syndrome}

\section{Badritdinova MN, Razhabova GKh, Akhmedova ShM, Akhmedova GI}

Department of Internal Diseases and Endocrinology, Faculty of General Medicine, Bukhara State Medical Institute, Bukhara, Uzbekistan.

\title{
ABSTRACT
}

Background: Diabetes mellitus and impaired glucose tolerance, in general, are more associated with the duration of painful episodes than normal glucose tolerance. However, in the presence of ischemic heart disease cardiac ischemia, the duration of painful episodes among patients with diabetes mellitus and impaired glucose tolerance is lower than among those without cardiac ischemia.

Objective: To study the specifics of the duration of a painful attack in patients with coronary artery disease in the presence of the main components of the metabolic syndrome.

Methods: Patienst with complaining of pain in the chest and his left hand were evaluated. In all patients parameters as blood pressure, body weight (Quetelet index), cholesterol, triglycerides, and glycemia were studied.

Results: The study of the relationship between the duration of painful attacks and the presence of hypertension showed that the presence of hypertension significantly increases both the risk of coronary artery disease as a whole and the appearance of ischemic changes on the electrocardiography. The study of the duration of painful attack depending on body weight showed that the duration of painful attack among cardiac ischemia patients is lower than among those without this disease.

Conclusion: The study suggests a link between the duration of painful attacks and the presence of the main components of metabolic syndrome. The data obtained to give a certain idea of the relationship between the duration of painful attacks in the chest and the presence of certain components of the metabolic syndrome.

Key Words: Hypertension, Hyperlipidemia, Diabetes, Abdominal obesity, Metabolic syndrome, Painful attack, Coronary heart disease

\section{INTRODUCTION}

The success of effective treatment and prevention of coronary artery disease is largely due to the early diagnosis of this disease. Currently, several diagnostic methods are used to detect CHD, which include a survey, electrocardiography (ECG), echocardiography (EchoCG), coronary angiography, various pharmacological tests, and exercise tests. ${ }^{1,2}$ The most accessible methods for diagnosing coronary artery disease in primary health care, where patients are the first to be interviewed and ECG. However, an ECG taken at rest does not always reveal ischemic changes in the myocardium.

The interrogative method for diagnosing IHD, proposed by Rose and Blackburn in 1968, is quite simple, economical, ac- cessible, and important for detecting IHD in outpatient conditions and conducting mass preventive examinations of the population. However, this method allows to detection only cases of typical angina of exertion when there is a clearly defined painful attack. At the same time, in their practical activity, doctors encounter cases of an atypical or painless course of the disease. In such cases, the value of this questionnaire is significantly reduced. ${ }^{3-5}$

Clinical and population-based studies have shown that diabetes mellitus (DM) has a significant effect on various characteristics of a painful attack. ${ }^{6,7}$ It has been shown that atypical or painless forms of the disease are often found in patients with diabetes mellitus suffering from coronary heart disease. In recent years, metabolic syndrome (MS), which is

\section{Corresponding Author:}

Badritdinova MN, Department of Internal Diseases and Endocrinology, Faculty of General Medicine, Bukhara State Medical Institute, Bukhara, Uzbekistan; E-mail: matlubabadritdinova17@gmail.com

ISSN: 2231-2196 (Print)

Received: 22.07 .2020
ISSN: $0975-5241$ (Online)

Revised: 14.09 .2020
Accepted: 28.10 .2020 
based on insulin resistance, is of great importance in the development of coronary heart disease. ${ }^{8,9}$ The presence of MS is associated with a higher risk of coronary artery disease and mortality from this disease. The main components of MS include hyperinsulinemia, arterial hypertension, hyperlipidemia, and obesity. ${ }^{10,11}$ The presence of individual components of MS can also have a definite influence on the characteristics of a painful attack in patients with IHD. The occurrence of the painful episode features in patients with coronary artery disease, depending on the presence of components of MS, can serve as an important aid inadequate, early diagnosis, prevention, and control of the treatment of coronary artery disease.

\section{MATERIAL AND METHODS}

The survey included 150 men complaining of pain in the chest and his left hand. The average age of the patients was $51,7+2,6$ years. In 108 of them, the diagnosis of IHD was not confirmed during the examination. 42 people were diagnosed with CHD. Moreover, the ECG of the 30 patients with coronary artery disease who were removed at rest revealed ischemic changes, and in 12 patients there were no such changes. Among those without ischemic changes on an ECG, a diagnosis of coronary artery disease was diagnosed alone was established based on a positive exercise test. All patients studied such parameters as blood pressure, body weight (Quetelet index), cholesterol, triglycerides, and glycemia (based on glucose tolerance test).

\section{RESULT}

The study showed that the duration of pain syndrome to a certain extent is associated with the presence of the main components of MS. The duration of pain in the group with impaired glucose tolerance (Table 1) was slightly higher than among individuals with normal tolerance, but these differences were not statistically significant.

Table 1: Duration of painful attack among persons with different glucose tolerance

\begin{tabular}{lccccc} 
CHD & Indicator stat. & There is no IHD & $\begin{array}{c}\text { IHD without } \\
\text { changes ECG }\end{array}$ & $\begin{array}{c}\text { IHD with changes } \\
\text { ECG }\end{array}$ & In general \\
NTG and diabetes & $\mathrm{n}$ & 65 & 7 & 15 & 87 \\
& $\mathrm{M}$ & 7.08 & $4.57^{*}$ & $4.53^{*}$ & 6.44 \\
& $\pm \delta$ & 0.45 & 0.25 & 0.34 & 0.44 \\
Diabetes & $\mathrm{n}$ & 7 & 1 & 2 & 10 \\
& $\mathrm{M}$ & 8.86 & 8.00 & $0.00 *$ & 7.40 \\
НТГ & 0.43 & 0 & 13 & 0.45 \\
& $\mathrm{n}$ & 36 & 4 & 4.62 * & 6.72 \\
& $\mathrm{M}$ & 7.78 & $4.00 *$ & 0.37 & 0.48 \\
\hline
\end{tabular}

CHD Indicator stat. No CHD treatments without ECG changes $\mathrm{CHD}$ with ECG changes in general. The table indicates the reliability of differences in indicators $(*)$ relative to the group without CHD.

However, among persons not suffering from coronary artery disease, the duration of painful attacks in diabetes was higher than among persons with normal tolerance. It is shown that among persons suffering from coronary artery disease (both with ECG changes and without ECG changes), the duration of the painful attacks is less than among those without CHD. Moreover, these differences (statistically significant) occur, both under normal and impaired glucose tolerance. This fact can be explained by the fact that among those without IHD, chest pain was like cardialgia, caused by other diseases that are different from IHD.
The study of the relationship between the duration of the painful attack and the presence of hypertension showed (Table 2) that the duration of painful attack among CHD patients is lower than among those without CHD. Moreover, the duration of a painful attack, both among patients without ischemic changes on the ECG, and with ischemic changes on the ECG were lower than among those without IHD. In general, among persons suffering from high blood pressure, the duration of painful attacks was less than among those with normal blood pressure. An exception is a group of patients with coronary artery disease with the presence of ischemic changes on the ECG. In this group, increased blood pressure was associated with a longer duration of pain attack. 
Table 2: The duration of painful attacks among people with hypertension

\begin{tabular}{lccccc} 
CHD & Indicator stat & There is no IHD & $\begin{array}{c}\text { IHD without ECG } \\
\text { changes }\end{array}$ & $\begin{array}{c}\text { IHD with ECG } \\
\text { changes }\end{array}$ & In general \\
The presence of hypertension & $\mathrm{N}$ & 76 & 10 & 15 & 101 \\
Normal & $\mathrm{M}$ & 7.75 & 4.90 & $3.33^{*}$ & 6.81 \\
$\mathrm{BP}$ & $\pm \delta$ & 0.48 & 0.24 & 0.29 & 0.47 \\
$\mathrm{AH}$ & $\mathrm{N}$ & 32 & 2 & 15 & 49 \\
& $\mathrm{M}$ & 6.66 & 3.50 & 5.47 * $\mathrm{0}$ & 6.16 \\
& $\pm \delta$ & 0.44 & 0.15 & 0.37 & 0.42 \\
\hline
\end{tabular}

$\mathrm{CH}$ Note: the table indicates the reliability of differences in the parameters of §) - relative to the group with normal blood pressure ${ }^{*}$ ) between groups of patients with IHD without and IHD.

Next was considered the duration of the painful attack, depending on body weight (Table 3). It turned out that the duration of painful attacks among IHD patients is lower than among those without this disease, both with normal and overweight. Among patients with coronary artery disease without ischemic changes on the ECG, the duration of painful attacks with increased body weight is lower than with normal body weight. In contrast, in the presence of ischemic changes on the ECG, the duration of the painful attacks is higher in persons with BMI and obesity than in normal body weight.

Table 3: Duration of painful attack among persons with different body weight

\begin{tabular}{lccccc} 
CHD & $\begin{array}{c}\text { Indicator There is IHD with- } \\
\text { stat } \\
\text { no IHD } \\
\text { out ECG } \\
\text { changes }\end{array}$ & $\begin{array}{c}\text { IHD } \\
\text { with } \\
\text { ECG } \\
\text { changes }\end{array}$ & In general \\
Normal & $\mathrm{n}$ & 76 & 10 & 15 & 101 \\
$\mathrm{AP}$ & $\mathrm{M}$ & 7.75 & $4.90^{*}$ & $3.33^{*}$ & 6.81 \\
& $\pm \delta$ & 0.48 & 0.24 & 0.29 & 0.47 \\
$\mathrm{AH}$ & $\mathrm{n}$ & 32 & 2 & 15 & 49 \\
& $\mathrm{M}$ & 6.66 & 3.50 & $5.47^{*} \S$ & 6.16 \\
& $\pm \delta$ & 0.44 & 0.15 & 0.37 & 0.42 \\
\hline
\end{tabular}

Note: the table indicates the reliability of differences in indicators ${ }^{*}$ - between groups of patients with IHD without and IHD. $\S)$ - between groups with normal and overweight

Dyslipidemia is one of the main components of metabolic syndrome. The presence of disorders of lipid metabolism is associated with an increased risk of developing coronary artery disease. In this regard, an attempt was made to analyze the duration of a painful attack depending on the presence of hypercholesterolemia (GH) and hypertriglyceridemia (THG).

According to the data obtained (Table 4), with a normal level of cholesterol, the duration of a painful attack is higher than with GC. Moreover, the duration of painful attacks, both at normal and elevated cholesterol levels, is higher among people without CHD.

Table 4: The duration of painful attacks among people with hypercholesterolemia

\begin{tabular}{lccccc}
$\begin{array}{l}\text { CHD } \\
\text { Level of } \\
\text { cholesterol }\end{array}$ & $\begin{array}{c}\text { Indicator There } \\
\text { stat } \\
\text { is no } \\
\text { IHD }\end{array}$ & $\begin{array}{c}\text { IHD } \\
\text { without } \\
\text { changes } \\
\text { ECG }\end{array}$ & $\begin{array}{c}\text { IHD } \\
\text { with } \\
\text { changes } \\
\text { ECG }\end{array}$ & $\begin{array}{c}\text { In } \\
\text { general }\end{array}$ \\
Normal level & $\mathrm{n}$ & 58 & 7 & 17 & 82 \\
& $\mathrm{M}$ & 7.84 & $4.86^{*}$ & $5.29^{*}$ & 7.06 \\
& $\pm \delta$ & 0.49 & 0.24 & 0.40 & 0.47 \\
Hypercho- & $\mathrm{n}$ & 50 & 5 & 13 & 68 \\
lesterinemia & $\mathrm{M}$ & 6.94 & 4.40 & $3.233^{*} \S$ & 6.04 \\
& $\pm \delta$ & 0.45 & 0.22 & 0.23 & 0.43 \\
\hline
\end{tabular}

Note: the table indicates the reliability of differences in performance. *between groups of patients with IHD without and IHD. sbetween groups with normal and elevated cholesterol levels.

It should be noted that the duration of painful attacks among patients with IHD was lower than with normal cholesterol levels. The least prolonged pain occurs in patients with coronary artery disease having ischemic changes on the ECG.

A somewhat different picture is observed about the relationship of hypertriglyceridemia (THG) with the duration of the pain attack (Table 5). In general, the presence of THG is associated with a longer duration of pain. At the same time, among patients with IHD, the duration of the painful attacks is lower than that of people without IHD, regardless of the presence of THG. 
Table 5: Duration of painful attack among persons with hypertriglyceridemia

\begin{tabular}{lccccc}
$\begin{array}{l}\text { CHD } \\
\text { Level of } \\
\text { cholesterol }\end{array}$ & $\begin{array}{c}\text { Indicator There is } \\
\text { stat }\end{array}$ & $\begin{array}{c}\text { IHD } \\
\text { no IHD } \\
\text { whanges } \\
\text { ECG }\end{array}$ & $\begin{array}{c}\text { IHD } \\
\text { with } \\
\text { changes } \\
\text { ECG }\end{array}$ & $\begin{array}{c}\text { In } \\
\text { general }\end{array}$ \\
Normal & $\mathrm{n}$ & 86 & 11 & 27 & 124 \\
level & $\mathrm{M}$ & 7.47 & $4.91 *$ & $4.26^{*}$ & 6.54 \\
& $\pm \delta$ & 0.48 & 0.23 & 0.35 & 0.46 \\
Hypertrigly- & $\mathrm{n}$ & 22 & 1 & 3 & 26 \\
ceridemia & $\mathrm{M}$ & 7.27 & 2.00 & 5.67 & 6.88 \\
& $\pm \delta$ & 0.44 & 0.00 & 0.33 & 0.44 \\
\hline
\end{tabular}

Note: the table indicates the reliability of differences in indicators *between groups of patients with IHD and without IHD.

Taking into account the obtained results on the relationship between individual components of the metabolic syndrome and the duration of pain in coronary artery disease, an attempt was made to assess the relationship between risk groups identified in the risk stratification of quantitative prognosis in patients with hypertension and the duration of pain. In the modern classification of hypertension, the criteria for stratifying patients were according to the degree of cardiovascular risk. These criteria include a large number of risk factors, target organ damage, and associated clinical conditions. Because this study focused on such components of MS as hypertension, IGT, dyslipidemia, obesity, and BMI, cardiovascular risk classification was carried out based on their presence. As it turned out (Figure 1), the duration of pain syndrome consistently increases with increasing risk. However, in the group of "very high" risk, there is a slight decrease in the duration of pain syndrome relative to the group with "high" risk. However, this reduction was not statistically significant.

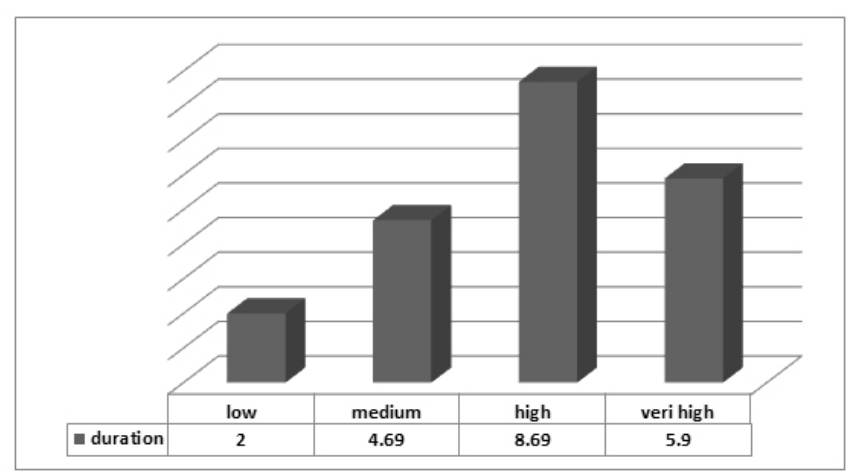

Figure 1: The duration of pain among persons with varying degrees of cardiovascular risk. An increase in the value of the indicators as the degree of risk increases is statistically significant, and the decrease is not significant.

\section{DISCUSSION}

The study suggests a link between the duration of painful attacks and the presence of the main components of MS. The data obtained to give a certain idea of the relationship between the duration of painful attacks in the chest and the presence of individual components of the metabolic syndrome. ${ }^{6,7}$ Diabetes mellitus and IGT, in general, are more associated with the duration of painful episodes than normal glucose tolerance. However, in the presence of IHD, the duration of painful episodes among patients with diabetes mellitus and IGT is lower than among those without IHD. The study of the relationship between the duration of painful attacks and the presence of hypertension showed that the presence of hypertension significantly increases both the risk of coronary artery disease as a whole and the appearance of ischemic changes on the ECG. The study of the duration of painful attack depending on body weight showed that the duration of painful attack among IHD patients is lower than among those without this disease. ${ }^{8,9}$ With normal body weight, pain episodes in IHD patients without ischemic changes on the ECG are 1.8 times longer than with ischemic changes. At the same time, the presence of BMI in IHD patients with ischemic changes on the ECG is associated with a longer (1.6 times) duration of painful attack than with normal body weight. In conditions of hypercholesterolemia, the duration of pain in IHD patients with ischemic changes on the ECG is 1.4 times longer than in IHD patients without ischemic changes. Even greater differences in these indicators are noted in hypertriglyceridemia. The duration of painful episodes in IHD patients with ischemic changes on the ECG in conditions of hyperglycemia is 2.8 times longer than among patients with IHD without ischemic changes on the ECG. ${ }^{10,11}$

The results of the analysis of the risk prediction of a quantitative prediction indicate that the degree of risk is associated with an increase in the duration of the pain attack. Considering the above data, it should be assumed that such components of MS as NTG, AH, BMI, and hypertriglyceridemia make a greater contribution to the duration of a painful attack and the degree of risk.

\section{CONCLUSION}

The clinical course of IHD is to a certain extent due to the presence of the main components of the metabolic syndrome, contributing to a change in the clinical picture of IHD. Increasing the duration of painful attacks in patients with IHD with such components of MS as NTG, hypertension UTI and hyperglycemia can serve as an indirect marker of the appearance of ischemic changes on the ECG. To prevent the formation and progression of coronary artery disease, all individuals with the presence of components of the metabolic syndrome should be conducted an ECG study and a survey to detect coronary artery disease. 


\section{ACKNOWLEDGMENT}

Authors acknowledge the immense help received from the scholars whose articles are cited and included in references to this manuscript. The authors are also grateful to authors / editors / publishers of all those articles, journals, and books from which the literature for this article has been reviewed and discussed.

Conflict of Interest: None

Source of Funding: None

\section{REFERENCES}

1. Rodolico A, Mineo L. Distinguishing Cardiac from Psychological Somatic Symptoms. In Book: Brain Heart Dyn 2020:181-96.

2. Al Suwaidi J, Higano ST, Holmes Jr DR, Lerman A. Pathophysiology, diagnosis, and current management strategies for chest pain in patients with normal findings on angiography. In: Elsevier Mayo Clinic Proceedings 2001;76(8):813-822.

3. Gutterman DD. Silent myocardial ischemia. Circulation J 2009;73(5):785-97.

4. Goldberg N, Sackner-Bernstein J, DePuey G. New concepts in the clinical aspects of cardiovascular disease. AIDS Read 2003;13(4): S25-S29.
5. Visser CL, Bilo HJ, Thomsen TF. Prediction of coronary heart disease: a comparison between the Copenhagen risk score and the Framingham risk score applied to a Dutch population. J Intern Med 2003;253(5):553-562.

6. Bhargava A. A longitudinal analysis of the risk factors for diabetes and coronary heart disease in the Framingham Offspring Study. Popul Health Metr 2003;1(1):3-9.

7. Clouse RE, Lustman PJ, Freedland KE, Griffith LS, McGill JB, Carney RM. Depression and coronary heart disease in women with diabetes. Psychosomatic Med 2003;65(3):376-383.

8. Chen W, Srinivasan SR, Li S, Xu J, Berenson GS. Clustering of Long-term Trends in Metabolic Syndrome Variables from Childhood to Adulthood in Blacks and Whites. Am J Epid 2007;166(5):527-533.

9. Tonstad S, Hjermann I. A high-risk score for coronary heart disease is associated with metabolic syndrome in 40-year-old men and women. J Cardiovascular Risk 2003;10(2):129-135.

10. Blomkalns AL, Lindsell CJ, Eady CE, Gibler W. The evaluation of hyperlipidemia in emergency department patients with the possible acute coronary syndrome. Acad Emerg Med 2003;10(5):429-437.

11. Laughlin GA, Barrett-Connor E, May S, Langenberg L. Association of Adiponectin with Coronary Heart Disease and Mortality. Am J Epid 2007;165(2):164-174. 